\title{
Confirmation of epidural catheter placement using nerve stimulation
}

Ban C.H. Tsui MSC MD,

Sunil Gupta MD FRCPC, Brendan Finucane MBBCH FRCPC

Purpose: To examine the reliability of low current electrical epidural stimulation to confirm epidural catheter placement.

Methods: Forty patients with epidural catheters ( $19 \mathrm{G}$ Arrow Flextip plus) already in place for post-operative pain management were studied. An adapter (Arrow-Johans ECG Adapter) was attached to the connector of the epidural catheter. The epidural catheter and adapter were filled with normal saline. The cathode lead of the nerve stimulator was attached to the metal hub of the adapter. Catheter placement was judged to be correct or incorrect, depending upon the presence or absence of truncal or limb movement to I $\mathrm{Hz}$ stimulation ( $1-10 \mathrm{~mA})$. A standard test dose ( $3 \mathrm{ml}$ lidocaine 1.5\% with 1:200,000 epinephrine) was then injected. The efficacy of the epidural morphine was assessed independently.

Results: The sensitivity and specificity of the test was 100\% and $91.6 \%$ compared with the standard test dose. The positive and negative predictive value was $96 \%$ and $100 \%$. In predicting the clinical effect of epidural morphine, the sensitivity and specificity was $96.1 \%$ and $76.9 \%$. The positive and negative predictive value was $89 \%$ and $90 \%$. The correlation of unilateral or bilateral motor response from the test and sensory response from the lidocaine test with sensitivity and specificity was $91.6 \%$ and $53.0 \%$. The predictive value for unilateral response was $61 \%$ and for bilateral was $88 \%$.

Conclusion: This study establishes this test as a simple, objective and reliable technique for confirmation of epidural catheter placement.

Objectif : Déterminer la fiabilité d'une stimulation péridurale électrique de faible intensité utilisée pour confirmer la mise en place d'un cathéter péridural.

Méthode : Quarante patients, à qui on avait déjà installé un cathéter péridural (Arrow Flextip plus 19G) pour traiter la douleur post opératoire, ont participé à l'étude. Un adaptateur (Arrow-Johans EXG Adapter) a été fixé au connecteur du cathéter. Ce cathéter et l'adaptateur ont été remplis de sérum physiologique. L'électrode cathodique du neurostimulateur a été fixée à la garde métallique de l'adaptateur. La mise en place du cathéter était jugée correcte ou incorrecte selon la présence ou l'absence d'un mouvement du tronc ou d'un membre à une stimulation de $\mathrm{I} \mathrm{Hz}(1-10 \mathrm{~mA})$. Une dose-test standard $(3 \mathrm{ml}$ de lidocaine à $1,5 \%$ avec I : 200000 d'épinéphrine) a été injectée par la suite. L'efficacité de la morphine péridurale a été évaluée séparément.

Résultats : La sensibilité et la spécificité du test étaient de $100 \%$ et de $91,6 \%$ en comparaison avec la dosetest standard. Les valeurs de la prédiction positive et négative étaient de $96 \%$ et de $100 \%$. Concernant la prédiction de l'effet clinique de la morphine péridurale, la sensibilité et la spécificité étaient de $96,1 \%$ et de $76,9 \%$. Les valeurs de la prédiction positive et négative étaient de $89 \%$ et $90 \%$. La corrélation entre une réponse motrice unilatérale ou bilatérale au test et une réponse sensorielle au test de lidocaïne avec sensibilité et spécificité était de $91,6 \%$ et $53,0 \%$. La valeur prédictive de la réponse unilatérale était de $61 \%$ et celle de la réponse bilatérale, de $88 \%$.

Conclusion : Cette étude reconnaît le test comme une technique simple, objective et fiable permettant la confirmation du placement d'un cathéter dans l'espace péridural.

From the Department of Anaesthesia, University of Alberta Hospitals, 3B2.32 Walter Mackenzie Health Sciences Centre, 8440-112 Street, Edmonton, Alberta, Canada T6G 2B7.

Address correspondence to: Dr. Ban C.H. Tsui. Phone: 403-492-8861; Fax: 403-492-9610

Presented in part at the Canadian Anaesthetists Society Annual Meeting, June 1998.

Accepted for publication February 25, 1998. 


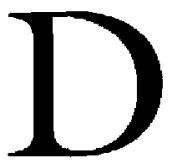

ESPITE the technical advances of the last $25 \mathrm{yr}$, there is still no reliable, objective, "on-the-spot" way of determining correct catheter placement in the epidural space. Diagnosis of intravascular or subarachnoid catheter placement is usually one of exclusion using the standard epidural test dose ( $3 \mathrm{ml}$ lidocaine $1.5 \%$ with $1: 200,000$ epinephrine). Ideally, one should be able to detect reliably when an epidural catheter is incorrectly sited whilst performing the procedure. This would allow adjustments to be made at the time of insertion. Furthermore, there are false positives and negatives associated with the standard test dose. ${ }^{1}$ To date, there is no reported practical technique that allows verification of epidural catheter position prior to local anaesthesia injection. ${ }^{2}$

Spinal cord stimulation techniques have been used in chronic pain therapy for ycars. ${ }^{3-5}$ Electrical stimulation methods are well accepted for identifying peripheral nerves when performing regional anesthesia. ${ }^{6,7}$ However, these methods have never been used to confirm catheter placement in the epidural space. To our knowledge, this is the first description of the use of low current epidural stimulation to confirm epidural catheter placement. The test that we describe here is a new objective method of confirming correct catheter placement in the epidural space. A positive motor response (truncal or limb movement) to epidural nerve stimulation indicates that the catheter is in the correct location. A lack of movement indicates that it is not.

\section{Methods}

\section{Study design}

Following institutional ethics committee approval and written informed consent, 40 patients with epidural catheters (19G Arrow Flextip plus, Arrow International, Inc., Reading, USA) already in place for post-operative pain management, were studied. Patients with implanted electronic devices (i.e. pacemaker, etc.) were excluded from the study. Informed consent was obtained from alert and oriented patients on postoperative day 1 or 2 .

Using a sterile technique (Figure), a nerve stimulator (Dakmed model 750 digital, C.R. Bard, Inc., Tewksbury, USA ) was connected to the existing epidural catheter via an adapter (Johans ECG Adapter, Arrow International, Inc., Reading, USA). The epidural catheter and ECG adapter were primed with sterile normal saline $(0.2$ to $1 \mathrm{ml})$. The anode terminal of the stimulator was connected to an electrode over the deltoid muscle. The cathode lead of the nerve stimulator was attached to the metal hub of the adapter. The nerve stimulator was set at a frequency of $1 \mathrm{~Hz}$ with a pulse width of $200 \mathrm{msec}$. The current

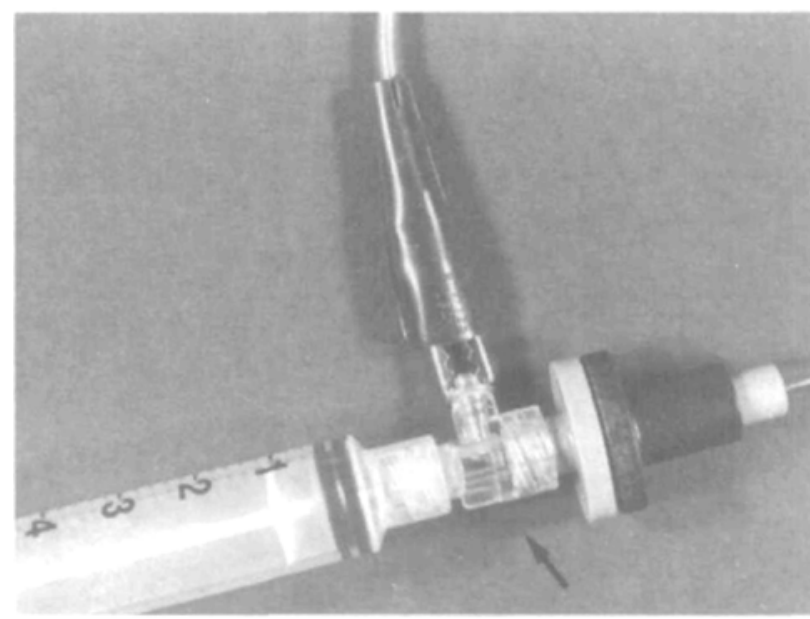

FIGURE Setup for monopolar stimulation via epidural catheter. Black arrow shows an Arrow-Johans ECG Adapter connected to snap-lock connector of the epidural catheter.

output was gradually increased from zero until motor activity was visible. Catheter placement was judged to be correct or incorrect depending upon the response to stimulation within a range of 1 to $10 \mathrm{~mA}$. With monopolar stimulation (as used in this study), ${ }^{6,7}$ the function of the anode electrode was primarily to serve as a grounding site for the conduction circuit. By altering the location of the grounding electrode, one could differentiate between a true positive test and local muscle or peripheral nerve stimulation. In the case of spinal cord stimulation, the strength and location of the motor response would not be changed in response to the placement of the grounding anode electrode. Any motor response secondary to local muscle or peripheral nerve stimulation would be altered by and respond to the placement of the grounding electrode. If local muscle contraction was observed at the site of the anode grounding electrode, the negative test was confirmed by observing relocation of the local muscle contraction following repositioning of the anode electrode over the deltoid muscle on the other side.

A test dose ( $3 \mathrm{ml}$ lidocaine $1.5 \%$ with 1:200,000 epinephrine) was then injected. Three to five minutes later, patients were assessed for changes in heart rate, blood pressure and sensory function. Objective sensory loss to pinprick was tested up to 20 min after the injection. The clinical effect of epidural morphine was assessed independently by anaesthetists from the acute pain service as satisfactory or not satisfactory.

\section{Equipment design}

EPIDURAL CATHETER

The key component of a functioning and effective 
TABLE I Comparison of the new test with the lidocaine test for 39 patients

\begin{tabular}{|c|c|c|c|c|}
\hline & \multicolumn{4}{|c|}{$\begin{array}{l}\text { standard test dose ( } 3 \mathrm{ml} \text { lidocaine } 1.5 \% \text { with } \\
1: 200,000 \text { epinephrine) }\end{array}$} \\
\hline & & Positive & Negatipe & Total \\
\hline \multirow[t]{3}{*}{ Test result } & positive & 27 & 1 & 28 \\
\hline & negative & 0 & 11 & 11 \\
\hline & & 27 & 12 & 39 \\
\hline
\end{tabular}

Sensitivity of the new test $=100 \%$

Specificity of the new test $=91.6 \%$

Positive Predictive Value $=96 \%$

Negative Predictive Value $=100 \%$

TABLE II Comparison of the new test with the clinical assessment by the acute pain service for 39 patients

\begin{tabular}{lllll}
\hline & \multicolumn{3}{c}{ Clinical effect of epidural morphine } \\
& & Good & Poor & Total \\
\hline Test result & positive & 25 & 3 & 28 \\
& negative & 1 & 10 & 11 \\
& & 26 & 13 & 39 \\
\hline
\end{tabular}

Sensitivity of the new test $=96.1 \%$

Specificity of the new test $=76.9 \%$

Positive Predictive Value $=89.2 \%$

Negative Predictive Value $=90 \%$

epidural anaesthetic is the successful delivery of an aqueous local anaesthetic solution into the epidural space. This delivery step is best demonstrated by continued conduction of an electrical impulse through a fluid medium rather than a wire to a fixed electrode located at the distal end of the catheter. In the test described, the electrical impulse is conducted through the injected fluid into the epidural space. This feature is important for testing and predicting a functional epidural catheter. If current is conducted through a wire connected to a distal electrode outside the lumen of the catheter, correct placement of the distal electrode may be detected, but proper delivery of the injected anaesthetic may not be reliably established. For instance, the injected anaesthetic may leak proximal to the epidural space if there is any damage to the catheter during insertion. However, air lock within the catheter or high impedance of the aqueous solution may hinder the flow of current down the length of the carheter tube in our system. Therefore, a catheter which has a metal element disposed within the lumen of the catheter tube is desirable to ensure proper conduction of electricity through the entire length of catheter. Based on the above requirements, the Arrow Flextip Plus catheter was utilized in this study.

\section{MODIFIED EPIDURAL CONNECTOR}

A modified epidural connector setup was used to connect the epidural catheter to a nerve stimulator. This arrangement involved attaching an adapter (Johans ECG adapter) to the epidural catheter connector. The main disadvantage of using an adapter is that it is prone to air lock within the adapter because only a small portion of the metal surface is exposed in the lumen of the adapter. Such an air lock may easily occur and hinder the flow of electricity down the catheter. Therefore, the meticulous removal of air bubbles must be carried out before performing the test. Ideally, a single unit, consisting of an epidural connector linked to a large conducting electrode should be used. As a single unit, the electrode can be placed much closer to the catheter than using an adapter such that it may reduce the chance of air lock between the electrode and metal element in the catheter as well as decrease the total impedance from the aqueous solutions. Furthermore, a single unit is not only less cumbersome and simpler to use but may also eliminate other

TABLE III Correlation of the unilateral or bilateral motor response from the new test and the sensory response from the lidocaine test

\begin{tabular}{|c|c|c|c|c|}
\hline & \multicolumn{4}{|c|}{$\begin{array}{l}\text { Sensory response from } 3 \mathrm{ml} \text { lidocaine } 1.5 \% \\
\text { with } 1: 200,000 \text { epinephrine }\end{array}$} \\
\hline & & Unilateral & Bilateral & Total \\
\hline \multirow[t]{3}{*}{ Motor response } & unilateral & 11 & 7 & 18 \\
\hline & bilateral & 1 & 8 & 9 \\
\hline & & 12 & 15 & 27 \\
\hline
\end{tabular}

Sensitivity of the new test $=91.6 \%$

Specificity of the new test $=53.0 \%$

Predictive Value for unilateral $=61 \%$

Predictive Value for bilateral $=88 \%$

TABLE IV Criteria for positive and negative test

Testing conditions:
ensuring the subject has not received any local anaesthetic via
epidural catheter or neuromuscular blocker before testing
Positive criteria 1 . The current needed should be within 1 to
10mA and the motor response may be unilat
eral or bilateral.
2. The motor response should be unchanged
in terms of strength or location regardless of
placement of the anode grounding electrode.
$\begin{aligned} & \text { 1. If the current needed is }<1 \text { mA, it is likely } \\ & \text { to be subarachnoid placement or directly } \\ & \text { against a nerve root. } \\ & \text { 2.The catheter is not in the epidural space } \\ & \text { and is likely posterior to the ligamentum } \\ & \text { flavum (i.e. subcutaneous): } \\ & \text { - if the subject does not respond at all, or } \\ & \text { - if the subject responds to a higher current } \\ & \text { (i.e. }>8 \text { mA) and the motor response changes } \\ & \text { in term of strength or location with reposi- } \\ & \text { tioning of the anode grounding electrode. }\end{aligned}$


potential problems such as accidental leakage from poor connections and inadvertent contamination during the connection of two separate pieces.

\section{Results}

Patients participating in this study did not complain of any pain or discomfort but were conscious of minor muscle twitching. Table I summarizes the comparison of this test with the lidocaine test for the 39 patients. There was a total of 28 positive and 11 negative test results from the new test. Comparison of the test result with the clinical assessment by the acute pain service of epidural morphine effect is shown in Table II. Table III shows the correlation of unilateral or bilateral motor response from the test and sensory response from the lidocaine test. The current needed to produce a positive test was 1.2 to $10 \mathrm{~mA}$ with an average of $3.78 \mathrm{~mA}$ in 28 positive test patients. Sensory block from the lidocaine test and truncal or limb movement from the positive test observed in this study ranged from $T_{7}-L_{5}$ (dermatomes and myotomes, respectively) both corresponding to the level of epidural catheter insertion. For the 11 negative tests, patients exhibited local muscle contraction (i.e. deltoid muscle) at a current range between 8 to $16 \mathrm{~mA}$ with an average of $11.4 \mathrm{~mA}$. These negative tests were confirmed by observing relocation of the local muscle contraction following repositioning of the anode electrode over the deltoid muscle on the other side. One patient whose catheter was subsequently found to be in the subarachnoid space (as demonstrated by clear CSF aspiration), showed a bilateral motor response with $0.4 \mathrm{~mA}$. This patient was not included in Table I and II. In another patient, the epidural catheter was inserted into the epidural space at a depth of $9 \mathrm{~cm}$ and a unilateral motor response was observed at a very low current of $0.5 \mathrm{~mA}$. However, a bilateral motor response was observed at $1.5 \mathrm{~mA}$ when the catheter was withdrawn $2 \mathrm{~cm}$.

\section{Discussion}

In a study by Abraham et al., ${ }^{8} 2-3 \mathrm{ml}$ lidocaine $1.5 \%$ epidural test dose provided good evidence of epidural anaesthesia with an objective sensory block by $20 \mathrm{~min}$ ( mean onset $8.8 \mathrm{~min}$ ) in the majority of patients ( 232 out of 235). Thus, an epidural test dose of $3 \mathrm{ml}$ lidocaine $1.5 \%$ was selected as the standard with which to compare the results of this new test. Table I shows acceptable values for this new test used to reliably confirm epidural catheter location. The only false positive result occurred in an elderly patient who was difficult to assess. Despite the positive test, the sensory changes were not clearly demonstrated with the lidocaine dose because the subjective answers from this patient were very ambiguous and inconsistent. Thus, it is likely that this single false positive result may have been mainly due to patient reporting problems rather than the accuracy of the test. One patient demonstrated a positive unilateral response at a very low current $(0.5$ $\mathrm{mA}$ ). No CSF or blood was aspirated from the catheter. Upon reviewing the anaesthesia record, the patients catheter was advanced $9 \mathrm{~cm}$ into the epidural space. However, a bilateral motor response was exhibited at $1.5 \mathrm{~mA}$, once the catheter was withdrawn $2 \mathrm{~cm}$. It is speculated that the reason for the unusually low current stimulation with unilateral response was explained by the proximity of the catheter tip to the nerve root. A single case of subarachnoid catheter placement was also observed with positive CSF aspiration from the catheter immediately after insertion. Thus, no medication was given through the epidural catheter. A bilateral motor response was exhibited at an unusually low current $(0.4 \mathrm{~mA})$. It is speculated that the typical characteristics of subarachnoid placement are bilateral response with very low current (i.e. $<1 \mathrm{~mA}$ ) as the CSF augments conduction to the nerve roots bilaterally through the CSF.

As shown in Table II, a slight discrepancy existed between the test and how members of the acute pain service interpreted the clinical effect of epidural morphine. There are a number of factors besides proper catheter placement that directly impact the efficacy of epidural morphine. Inadequate dosage, inappropriate dosing frequency, extent of surgery and low pain threshold can all affect the clinical effects of epidural morphine. All of these factors could have introduced a discrepancy in the assessment of the test and the clinical outcome assessment. For instance, two patients with positive tests who complained of inadequate pain control from epidural morphine were later discovered to have not received any epidural morphine for $24 \mathrm{hr}$. On these two occasions, both patients had satisfactory pain relief from epidural morphine after appropriate epidural morphine dosing was instituted. One of the interesting observations of this study was an unexpectedly high incidence of unsatisfactory pain relief from epidural anaesthesia (33\%), discovered in the post-operative period. The majority of the catheter failures seem to be due to unintentional catheter withdrawal as a result of inadequate taping or increased patient activity.

Table III shows a large discrepancy existed between the unilateral or bilateral motor response from the test and the sensory response from the lidocaine test. This variation might be expected as the test may only provide a rough indication as to whether the tip of the catheter lies closer to one side or the other. Because local anaesthetics are liquid, they distribute to both 
sides of the epidural space even if the tip of the catheter is slightly closer to one side. Therefore, the bilateral sensory response from the lidocaine test dose may occur even in subjects with unilateral motor response from the test. The sensitivity of detecting potential unilateral blocks from the test is reasonably good with $92 \%$. The predictive value for bilateral block is also high ( $88 \%)$. In predicting unilateral local anesthetic block, the test is poor $(61 \%)$.

Based on the available data, the positive and negative test criteria are developed as in Table IV. However, these findings require cautious interpretation. Because of the small number of patients studied to date, the milliamperage current settings are intended as guidelines and may require adjustment as experience increases. Ideally, patients entering this study should have been randomly selected and the treatment groups should have been blinded. Since patient and observer blinding would have been difficult to achieve because of the motor response, observer blindness was not thought to be warranted for practical and financial reasons. All tests were carried out by the principle author, therefore, subtle bias may have existed in this study. The cases of subarachnoid placement and possible nerve root placement makes the generalization of the data from these cases difficult. The interpretation of the test with other possible catheter misplacement positions including intravascular and subdural placement remain unanswered from this study.

Since this test relies only on objective observation of motor movement, it appears to be suitable for testing in a wide variety of patient groups varying from conscious and oriented patients to unconscious and those not capable of verbal communications. On the other hand, the local anaesthetic test dose depends on subjective evaluation and the results tend to be variable and time consuming.

In conclusion, this new test seems to be not only reliable but it is also a potentially time saving technique avoiding the risk of using a standard local anaesthetic test dose to confirm epidural placement in postoperative pain care. Since the test can be performed with one of the commonly available epidural catheters, it can be readily applied in routine practice as an adjuvant technique to improve the success rate of epidural anesthesia and as a useful teaching tool in a clinical setting.

\section{References}

1 Dain SL, Rolbin SH, Hew EM. The epidural test dose in obstetrics: is it necessary? Can J Anaesth 1987; 34: 601-5.

2 Stevens RM. Neuraxial blocks. In: Brown DL (Ed.). Regional Anesthesia and Analgesia. Philadelphia: WB Saunders Company, 1996: 319-56.
3 Kumar K, Nath R, Wyant GM. Treatment of chronic pain by epidural spinal cord stimulation: a 10 -year experience. J Neurosurg 1991; 75: 402-7.

4 North $R B$. Spinal cord stimulation for chronic intractable pain. In: Devinsky O, Beri A, Dogali M (Eds.). Advances in Neurology, Vol 63. Electrical and Magnetic Stimulation of the Brain and Spinal Cord. New York: Raven Press, 1993: 289-301.

5 Sherwood $A M$. Biomedical engineering aspects of spinal cord stimulation. Proceedings of the 3rd International Meeting on Spinal Cord Stimulation, Houston 1980. Appl. Neurophysiol 1981; 44: 126-32.

6 Pither C. Nerve stimulation. In: Raj PP (Ed.). Clinical Practice of Regional Anesthesia. New York: Churchill Livingstone, 1993: 161-9.

7 Bridenbaugh PO. Patient management for nerual blockade: selection,management, premedication, and supplementation. In: Cousins MJ, Bridenbaugh PO (Eds.). Neural Blockade in Clinical Anesthesia and Management of Pain, 2nd ed. Philadelphia: JB Lippincott, 1988: 191-210.

8 Abrabam RA,Harris AP,Maxivell LG, Kaplow S. The efficacy of $1.5 \%$ lidocaine with $7.5 \%$ dextrose and epinephrine as an epidural test dose for obstetrics. Anesthesiology 1986; 64: 116-19. 